\title{
Phosphorylation of $\beta$-catenin results in lack of $\beta$-catenin signaling in melanoma
}

\author{
SILKE KUPHAL and ANJA KATRIN BOSSERHOFF \\ Institute of Pathology, University of Regensburg, D-93053 Regensburg, Germany
}

Received February 8, 2011; Accepted March 30, 2011

DOI: $10.3892 /$ ijo.2011.1028

\begin{abstract}
The Wnt/ $\beta$-catenin pathway is involved in differentiation events during embryonic development and is further described as a pathway often participating in tumor formation when aberrantly activated. Molecular studies concentrating on colorectal cancer revealed mutations of apc, ctnnbi, btrc and $t c f-4$ genes which mimic Wnt stimulation. However, such mutations are rarely found during melanoma development. Therefore, we analyzed the $\beta$-catenin activity in this type of skin cancer. Interestingly, localization of $\beta$-catenin protein was basically cytoplasmic in melanomas in vivo, which was in clear contrast to findings in colon carcinoma. Congruently, the transcriptional activity of $\beta$-catenin regulating expression of $\beta$-catenin target genes was not observed in several melanoma cell lines. Further, neither $\mathrm{LiCl}$ nor Wnt agonist treatment led to significant activation of $\beta$-catenin signaling. This lack in functionality seems to depend on phosphorylation at threonine 41 and serine 45 of $\beta$-catenin observed in several melanoma cell lines. However, this specific endogenous phosphorylation pattern led to upregulation of other signaling pathways resulting e.g. in induction of $\mathrm{N}$-cadherin expression. In summary, this study suggests a cell type-specific regulation of $\beta$-catenin function. This alternative $\beta$-catenin signaling pathway should be considered when thinking about targeting $\beta$-catenin in melanoma treatment.
\end{abstract}

\section{Introduction}

The $\beta$-catenin protein was initially discovered for its role in cell adhesion (1). As a component of adherens junctions, it promotes cell adhesion by binding to the intracellular domain of the trans-membrane protein cadherin linking it to the actin cytoskeleton through the adaptor protein $\alpha$-catenin.

Additionally, the signaling function of $\beta$-catenin in the so-called canonical Wnt pathway is conferred by a soluble

Correspondence to: Dr Silke Kuphal, University of Regensburg, Institute of Pathology, Franz-Josef-Strauss-Allee 11,93053 Regensburg, Germany

E-mail: skuphal@gmx.de

E-mail: silke.kuphal@klinik.uni-regensburg.de

Key words: melanoma, phosphorylated/hypophosphorylated $\beta$-catenin cyto-plasmic pool whose stability is tightly regulated. Strong phosphorylation of $\beta$-catenin at its $\mathrm{N}$-terminal region (serine 33, serine 37, serine 45 and threonine 41) labels the molecule for proteasomal degradation. Several molecules are believed to be responsible for phosphorylation of $\beta$-catenin at the N-terminus: the serine/threonine kinase GSK- $\beta$ (glycogen synthase kinase $3 \beta$ ) (2), Dsh (dishevelled), APC (Adenomatous polyposis coli), Axin, PP2A (protein phosphatase $2 \mathrm{~A}$ ) and CKI (casein kinase $1 \alpha$ and $\varepsilon$ ) (3).

Wnt signals lead to accumulation of $\beta$-catenin. Certain Wnt molecules, mainly Wnt1, Wnt2, Wnt3, Wnt3a and Wnt8 bind to Frizzled/LRP (low-density lipoprotein receptor-related protein) receptors which results in the inhibition of the APC-Axin-GSK-3 $\beta$ complex by activation of Dishevelled (4) and by recruitment of Axin to the plasma membrane (5). This results in an increase in hypophosphorylated $\beta$-catenin that forms active transcriptional complexes with LEF/TCF transcription factors in the nucleus (6).

At least one other Wnt signaling pathway exists often named as non-canonical Wnt signaling. The non-canonical pathway is induced by other Wnts such as Wnt5a, Wnt5b, Wnt4 and Wnt11 and can trigger intracellular calcium release (7) and activation of PKC (protein kinase C) and CamKII (calmodulin kinase II) (8). The involvement of Wnt5a in cell motility and invasion of melanoma cells was described recently showing an increase in activated PKC (9). This non-canonical pathway does not directly regulate $\beta$-catenin but it modulates the transcriptional activity of LEF/TCF in the nucleus.

Most oncological findings regarding the $\mathrm{Wnt} / \beta$-catenin signaling came from the analysis of colon, breast and kidney carcinoma $(10,11)$ where activation of the pathway has been directly implicated in disease pathogenesis. The majority of colorectal carcinomas carry inactivating mutations in the Adenomatous polyposis coli (APC) tumor suppressor which lead to stabilization of $\beta$-catenin (12). Additionally, mutations in the $\beta$-catenin gene $C T N N B I$ were found in colon cancer leading to the constitutive activation of $\beta$-catenin/LEF/TCF-dependent canonical signaling (13). All these studies demonstrating the activation of this pathway in cancer have the idea that elevated $\mathrm{Wnt} / \beta$-catenin signaling is oncogenic in most contexts.

Studies of $\beta$-catenin mainly have been carried out in epithelial cells of colon or breast carcinomas but rarely in cell types of other embryonic origins. In malignant melanoma, a tumor originating from melanocytes derived from the neural crest, data on $\beta$-catenin signaling are still conflicting. 
CTNNBI gene mutations (2-22\%) as well as APC mutations $(2.5 \%)$ are rare in malignant melanoma (14-16). Hypermethylation of the APC promoter $1 \mathrm{~A}$ seems to be more frequent (15\% of cell lines and biopsy samples) but does not necessarily increase $\beta$-catenin activity (16). Indeed, $\beta$-catenin is found only in $\sim 6-30 \%$ of human melanoma nuclei, indicating that alternative localization of $\beta$-catenin or activation of further signaling pathways could have more relevance in melanoma than the translocation of $\beta$-catenin into the nucleus (17). On the contrary, the observed presence of nuclear $\beta$-catenin in the majority of benign nevi, along with the loss of nuclear $\beta$-catenin seen in melanoma progression (18-21), support the hypothesis that activation of nuclear Wnt/ $\beta$-catenin signaling is important for a controlled cellular homeostasis of the skin.

Data from our laboratory provide evidence for the importance of an alternative $\beta$-catenin signaling in the cytoplasm of melanoma cells. Cytoplasmic $\beta$-catenin activates the MAPKinase $\mathrm{p} 38$ and the NF- $\mathrm{kB}$ signaling pathway in malignant melanoma inducing $\mathrm{N}$-cadherin expression $(22,23)$.

In this study, we aimed to investigate the function of $\beta$-catenin in melanoma cells and to clarify the mechanisms leading to a different signaling function of $\beta$-catenin in melanoma compared to epithelial cells and carcinomas.

\section{Materials and methods}

Cell lines and cell culture conditions. Cell lines and culture conditions were previously described (24). The colon carcinoma cell line SW480 was generated from a primary adenocarcinoma and exhibits no $\beta$-catenin mutation. The melanoma cell line 501 mel exhibits a D32H mutation of $\beta$-catenin (25). In experiments cells were treated with 40 or $20 \mathrm{mM}$ lithium chloride (Sigma-Aldrich, Steinheim, Germany)

Molecular constructs. The following constructs were generous gifts: pBAT- $\beta$-catenin from J. Behrens (Department of Experimental Medicine II, University of Erlangen, Germany), T41A and S45A from D.L. Rimm (Department of Pathology, Yale University School of Medicine, New Haven) (26).

Transfection experiments and luciferase measurements. Transient transfections experiments were described previously (27). For transient transfection the plasmids TOPflash/ FOPflash $(0.5 \mu \mathrm{g} /$ well) (Upstate, Lake Placid, NY, USA) were used. The Renilla vector was used to normalize the transfection efficiency.

Western blotting. Cells $\left(3 \times 10^{6}\right)$ were lysed in $200 \mu$ l RIPAbuffer (Roche, Mannheim, Germany). Cell lysate (5-40 $\mu \mathrm{g}$ ) was separated on $10 \%$ SDS-PAGE gels and subsequently blotted onto a PVDF membrane. After blocking with $3 \%$ BSA/PBS the membrane was incubated for $16 \mathrm{~h}$ with one of the following antibodies: anti- $\beta$-catenin ( 1 in 3000 dilution) (Sigma), antihypophosphorylated $\beta$-catenin (35-50) (1 in 200 dilution) (Acris, Hiddenhausen, Germany), anti-hypophosphorylated $\beta$-catenin (27-37) (1 in 200 dilution) (upstate), anti- $\beta$-cateninphospho 41/45 (1 in 500 dilution) (Cell Signaling), anti- $\beta$-catenin phospho S33 (1 in 500 dilution), anti- $\beta$-catenin phospho S37 ( 1 in 500 dilution), anti- $\beta$-catenin phospho T41 (1 in 500 dilution), anti- $\beta$-catenin phospho S45 (1 in 500 dilution),
(Abcam, Cambridge, UK), and anti- $\beta$-actin (1 in 5000 dilution) (Sigma).

Quantitative real-time PCR for Brn-2 and laminin $\gamma 2$. Quantitative real-time PCR was performed on a Lightcycler (Roche, Mannheim, Germany) basically as described (27). The following PCR program was used: $30 \mathrm{sec} 95^{\circ} \mathrm{C}$ (initial denaturation); $20^{\circ} \mathrm{C} / \mathrm{sec}$ temperature transition rate up to $95^{\circ} \mathrm{C}$ for $15 \mathrm{sec}, 3 \mathrm{sec} 60^{\circ} \mathrm{C}, 5 \sec 72^{\circ} \mathrm{C}, 85^{\circ} \mathrm{C}$ acquisition mode single, repeated for 40 times (amplification). The PCR reaction was evaluated by melting curve analysis.

Immunohistochemistry. The paraffin-embedded tissues were deparaffinized, rehydrated and subsequently incubated with primary rabbit anti- $\beta$-catenin antibody (Sigma, 1:40) and primary mouse anti-E-cadherin antibody (BD Biosciences, 1:40) over night at $4^{\circ} \mathrm{C}$. The secondary antibody (biotin-labeled anti-rabbit/anti-mouse; Dako, Hamburg, Germany) was incubated for $30 \mathrm{~min}$ at room temperature, followed by incubation with streptavidin-POD (Dako) for $30 \mathrm{~min}$. Antibody binding was visualized using AEC-solution (Dako). Finally, the tissues were counterstained by hemalaun solution (Dako). The evaluation of the staining was performed semi-quantitatively by light microscopy.

Immunofluorescence. Cells $\left(5 \times 10^{5}\right)$ were grown on a chamber slide for one day and incubated with lithium chloride $(20 \mathrm{mM})$ for $4 \mathrm{~h}$. The cells were fixed with $4 \%$ paraformaldehyde, incubated with $0.1 \%$ Triton X-100 (Sigma) and covered with blocking solution (PBS/1\% BSA) for $1 \mathrm{~h}$. Thereafter, cells were incubated with $\beta$-catenin antibody (1 in 100 dilution) for $1 \mathrm{~h}$. The secondary antibody was FITC-conjugated antibody (1 in 40 dilution) (Dako, Glostrup, Denmark). After mounting with Mounting Medium with DAPI (Vectashield, H-1500) images were collected by fluorescence microscopy.

Subcellular proteome extraction kit. The extraction was performed using the subcellular proteome extraction kit following the manufacturer's (Calbiochem) instructions.

Statistical analysis. Results are expressed as the mean \pm SD. Comparison between groups was made using the Student's unpaired t-test. $\mathrm{p}<0.05$ was considered statistically significant and marked with asterisks in the figures (ns, not significant). All calculations were performed using the Graph Pad Prism software (GraphPad software Inc., San Diego, CA, USA).

\section{Results}

The current study was designed to elucidate the role of $\beta$-catenin in melanoma cells. Several studies suggest an important role of $\beta$-catenin in malignant melanoma (18) however, classical target genes of $\beta$-catenin such as c-myc or laminin $\gamma 2$ were only rarely found to be induced in melanomas.

Endogenous status of $\beta$-catenin expression in malignant melanoma. To examine $\beta$-catenin expression in vivo, we stained tissue samples from patients with primary malignant melanomas. Representative sections are presented in Fig. 1A. The distribution of $\beta$-catenin in healthy skin was basically restricted 

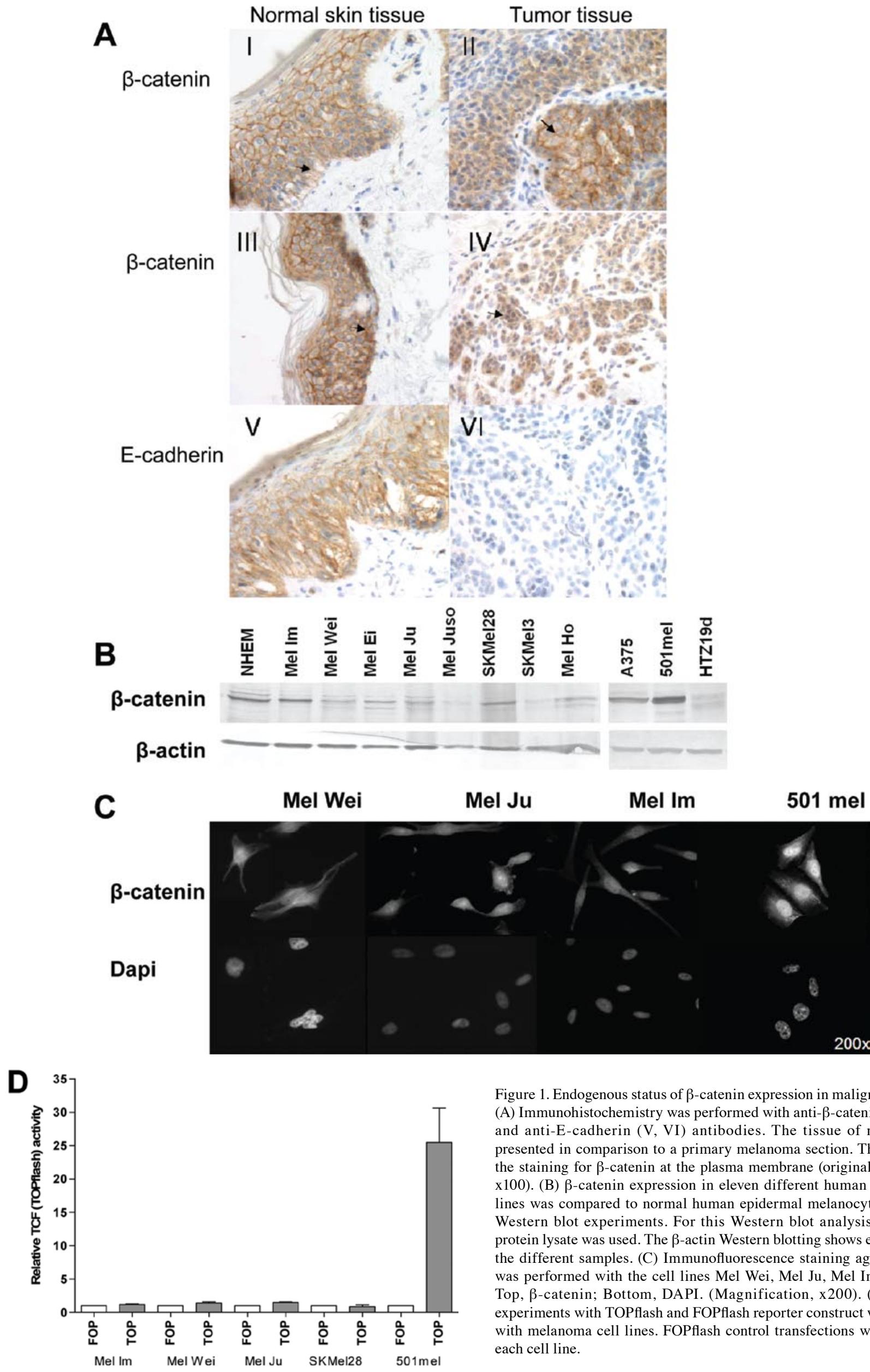

Figure 1. Endogenous status of $\beta$-catenin expression in malignant melanoma. (A) Immunohistochemistry was performed with anti- $\beta$-catenin (I, II, III, IV) and anti-E-cadherin (V, VI) antibodies. The tissue of normal skin is presented in comparison to a primary melanoma section. The arrow shows the staining for $\beta$-catenin at the plasma membrane (original magnification, $\mathrm{x} 100)$. (B) $\beta$-catenin expression in eleven different human melanoma cell lines was compared to normal human epidermal melanocytes (NHEM) in Western blot experiments. For this Western blot analysis $10 \mu \mathrm{g}$ overall protein lysate was used. The $\beta$-actin Western blotting shows equal loading of the different samples. (C) Immunofluorescence staining against $\beta$-catenin was performed with the cell lines Mel Wei, Mel Ju, Mel Im and 501 mel. Top, $\beta$-catenin; Bottom, DAPI. (Magnification, x200). (D) Luciferase experiments with TOPflash and FOPflash reporter construct were performed with melanoma cell lines. FOPflash control transfections were set as 1 for each cell line. 
to the membrane of keratinocytes and melanocytes (I, III) where E-cadherin $(\mathrm{V})$ is localized. The melanoma samples showed $\beta$-catenin immunostaining in the cytoplasm and at the membrane (II, IV) however, no obvious $\beta$-catenin expression was detectable in the nucleus of tumor cells. As already known, melanomas showed loss of E-cadherin expression (VI). Our findings were confirmed by images on the homepage of the human protein atlas (www.proteinatlas.org) where a small tissue microarray of 12 malignant melanoma tissues showed staining of $\beta$-catenin in the cytoplasm and at the membrane in 12 of 12 melanoma cases. Only 2 of the 12 melanoma tissues present additional nuclear staining.

The endogenous levels of $\beta$-catenin in eleven different melanoma cell lines (Mel Wei, Mel Ei, Mel Juso, A375 derived from primary melanomas; Mel Im, Mel Ju, SKMel28, SKMel3, HTZ19d, 501 mel and Mel Ho derived from melanoma metastasis) were determined compared to normal human epidermal melanocytes (NHEM) in Western blot analysis. Here all cells, beside the cell line $501 \mathrm{mel}, \mathrm{A} 375$ and melanocytes, showed relatively low amounts of $\beta$-catenin (Fig. 1B).

The cell line 501 mel was described in detail in the publication of Rubinfeld et al (28) as a cell line with strong $\beta$-catenin protein expression leading to activated $\mathrm{Wnt} / \beta$-catenin signaling. As $501 \mathrm{mel}$ is described to exhibit transcriptional active $\beta$-catenin we chose this cell line as positive control for the canonical Wnt signaling pathway in the further analysis.

Next, the sub-cellular distribution of $\beta$-catenin was determined by immunofluorescence staining. Anti- $\beta$-catenin staining of melanoma cell lines Mel Wei, Mel Ju and Mel Im revealed apparently similar amounts of $\beta$-catenin in nucleus and cytoplasm (Fig. 1C). The melanoma cell line 501 mel showed elevated $\beta$-catenin accumulation in the nucleus (Fig. 1C).

Next to protein localization the activity of the Wnt/ $\beta$-catenin pathway is an important read-out. The transcriptional activity of $\beta$-catenin was analyzed using the TCF luciferase reporter constructs termed TOPflash and the mutant control FOPflash. The transfection efficiency was normalized by co-transfection of a renilla (pRLTK) construct. Only minor LEF/TCF activity was revealed in melanoma cell lines Mel Im, Mel Wei, Mel Ju and SKMel28 whereas strong activity was observed in the melanoma cell line 501 mel (Fig. 1D).

We revealed that in melanoma in vivo $\beta$-catenin is localized predominantly in the cytoplasm of the cells. The analyzed melanoma cell lines Mel Wei, Mel Ju and Mel Im displayed an equal distribution of $\beta$-catenin in cytoplasm and nucleus which is different to the melanoma cell line 501 mel which showed accumulated $\beta$-catenin protein levels in the nucleus. These findings, supported by the lack of transcriptional activity in several melanoma cell lines, were very surprising with respect to the current literature.

Analysis of transcriptional activity of $\beta$-catenin. Fig. 1 shows heterogeneity of the analyzed melanoma cell lines regarding $\beta$-catenin protein amount, cellular $\beta$-catenin locali-zation and transcriptional activity.

Next, stabilization and translocation of $\beta$-catenin into the nucleus was induced by treatment with lithium chloride $(\mathrm{LiCl})$. $\mathrm{LiCl}$ is an inhibitor of GSK-3 $\beta$ activity and is widely used to mimic Wnt signaling. The Western blots in Fig. 2A show relatively low levels of $\beta$-catenin in the untreated (control; lanes 1 and 3) melanoma cell lines Mel Im, Mel Wei and Mel $\mathrm{Ju}$ in cytoplasm and nucleus. Particularly, the analysis of the nuclear protein extract (control; lane 3) revealed low amounts of nuclear $\beta$-catenin in Mel Im, Mel Wei and Mel Ju. The positive control 501 mel displayed higher protein amounts of $\beta$-catenin in general (control; lanes 1 and 3) and enhanced accumulation of $\beta$-catenin in the nucleus (control; lane 3 ) in special. $\mathrm{LiCl}$ treatment $(40 \mathrm{mM})$ led to a nuclear and cytoplasmic increase of $\beta$-catenin in all melanoma cell lines used in the study after $4 \mathrm{~h}$ incubation time, as shown by Western blot (LiCl; lanes 2 and 4; Fig. 2A). Additionally, we determined the nuclear translocation of $\beta$-catenin after $\mathrm{LiCl}$ treatment with immunofluorescence analysis in several melanoma cell lines (data not shown). These Western blots and immunofluorescence data indicated that the mechanism of nuclear import of $\beta$-catenin is functional in melanoma cells but remains low under physiological conditions.

To analyze primary and early effects of $\mathrm{LiCl}$ on the transcriptional activity of $\beta$-catenin we again used the TCF luciferase reporter. Although enhanced nuclear $\beta$-catenin was found after $\mathrm{LiCl}$ treatment for $4 \mathrm{~h}(40 \mathrm{mM})$, significant stimulation of the TOPflash reporter construct was not measurable in Mel Im, Mel Wei, Mel Ju and SKMel28 (Fig. 2B). As a control, the melanoma cell line 501 mel showed high transcriptional activation of TCF activity in general which was significantly enhanced after stimulation with $\mathrm{LiCl}$. Only a long-term incubation with $\mathrm{LiCl}$ for $24 \mathrm{~h}$ led to a slight induction of TCF luciferase activity in the cell lines Mel Im, Mel Wei, Mel Ju and SKMel28 (Fig. 2B). However, again the positive control 501 mel exhibits higher transcriptional activity of $\beta$-catenin compared to the other melanoma cell lines. Taken together, these results indicate that short-term stimulation of Wnt signaling did not result in significant activation of $\beta$-catenin transcriptional activity in every melanoma cell line although a shift of $\beta$-catenin into the nucleus after treatment with $\mathrm{LiCl}$ was visible.

Phosphorylation of endogenous $\beta$-catenin. $\beta$-catenin signaling can be constitutively activated by truncation or mutation of serine and threonine residues in exon 3 . As a result, an $\mathrm{N}$-terminally hypophosphorylated form of $\beta$-catenin accumulates, translocates to the nucleus, and activates LEF/ TCF transcriptional activity. Therefore, we became interested in the phosphorylation status of $\beta$-catenin in the melanoma cell lines.

Analysis with an antibody detecting hypophosphorylated $\beta$-catenin at amino acids (aa) 27-37 showed these aa, including the regulative important serine 33 and serine 37 , to be hypohosphorylated in melanoma cells whereas the use of an antibody detecting hypophosphorylated $\beta$-catenin at position aa35-50 revealed that this region, including threonine 41 and serine 45 , is phosphorylated in several melanoma cell lines (Fig. 3A). The control cell lines SW480 and 501 mel showed the expression of hypophosphorylated $\beta$-catenin at the specific aa. We confirmed the results by using antibodies detecting the specific phosphorylation of serine 45 , threonine 41 , serine 37 and serine 33. The cell lines $501 \mathrm{mel}$, SKMel28 and Mel Im were analyzed for their phosphorylation status of $\beta$-catenin in cytoplasmic extracts (Fig. 3B). Serine 33 and serine 37 were not phosphorylated in all cell lines compared to a positive 

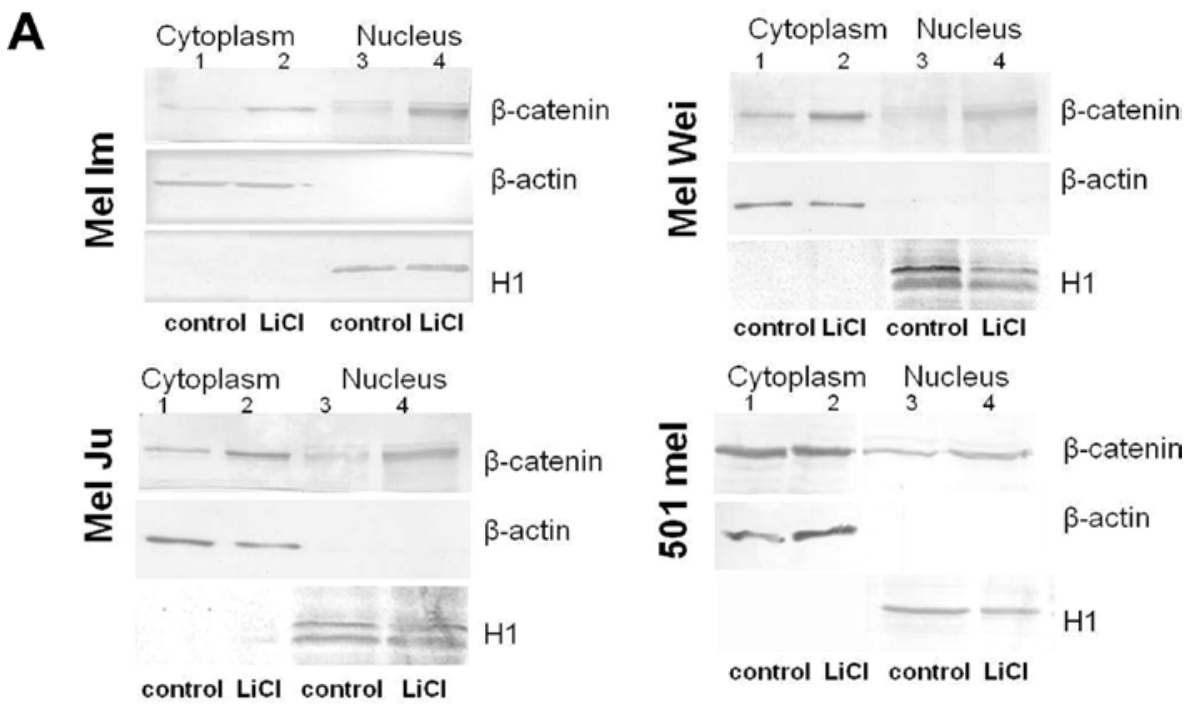

B
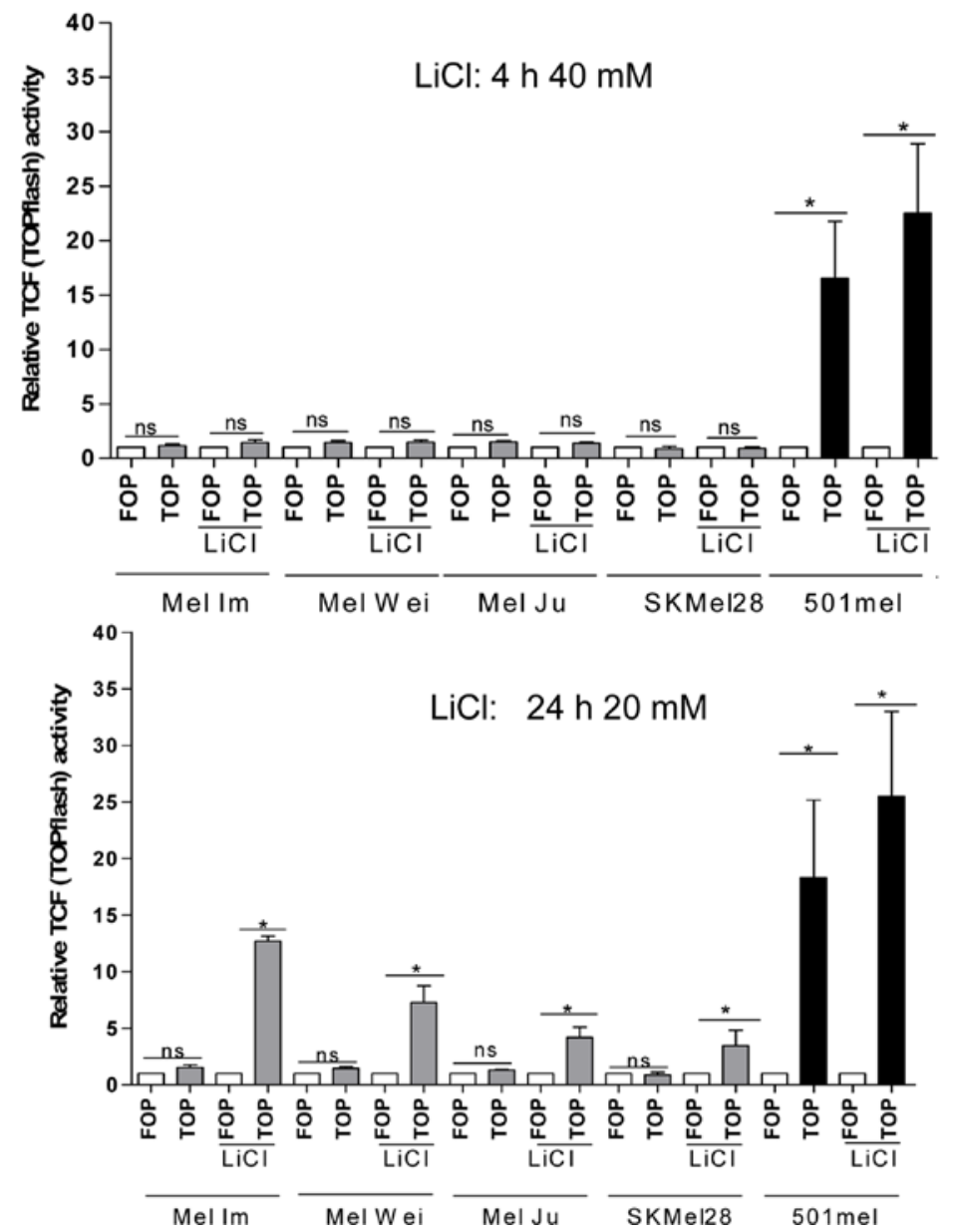

Figure 2. Localization of $\beta$-catenin in malignant melanoma. Analysis of transcriptional activation of $\beta$-catenin. (A) Cytoplasmic and nuclear protein extracts of Mel Im, Mel Wei, Mel Ju and 501 mel cells [either untreated or treated with lithium chloride (LiCl)] were analyzed by Western blots using an anti- $\beta$-catenin antibody. $\beta$-actin and $\mathrm{H} 1$ (histone H1) staining are loading and quality controls for the cytoplasmic and nuclear extracts. (B) Reporter gene analyses with TOPflash and FOPflash reporter construct were performed. FOPflash control transfections were set as 1 for each cell line. TOPflash activity was analyzed after incubation of the cell lines Mel Im, Mel Wei, Mel Ju, SKMel28 and 501 mel with lithium chloride (LiCl) for 4 and 24 h, respectively. ("p $<0.05$; ns, not significant).

control provided (breast carcinoma tissue, SW626 cells). However, threonine 41 and serine 45 were phosphorylated in SKMel 28 and Mel Im in comparison to the control $501 \mathrm{mel}$.

In conclusion, we revealed marked differences in phosphorylation of threonine 41 and serine 45 comparing $\beta$-catenin in melanoma cell lines (Fig. 3C). We speculated that only $\beta$-catenin of 501 mel is hypophosphorylated and has LEF/ TCF transcriptional activity.

It is suggested that hypophosphorylated $\beta$-catenin at Ser33, Ser37 and Thr41 is more transcriptionally active than forms 


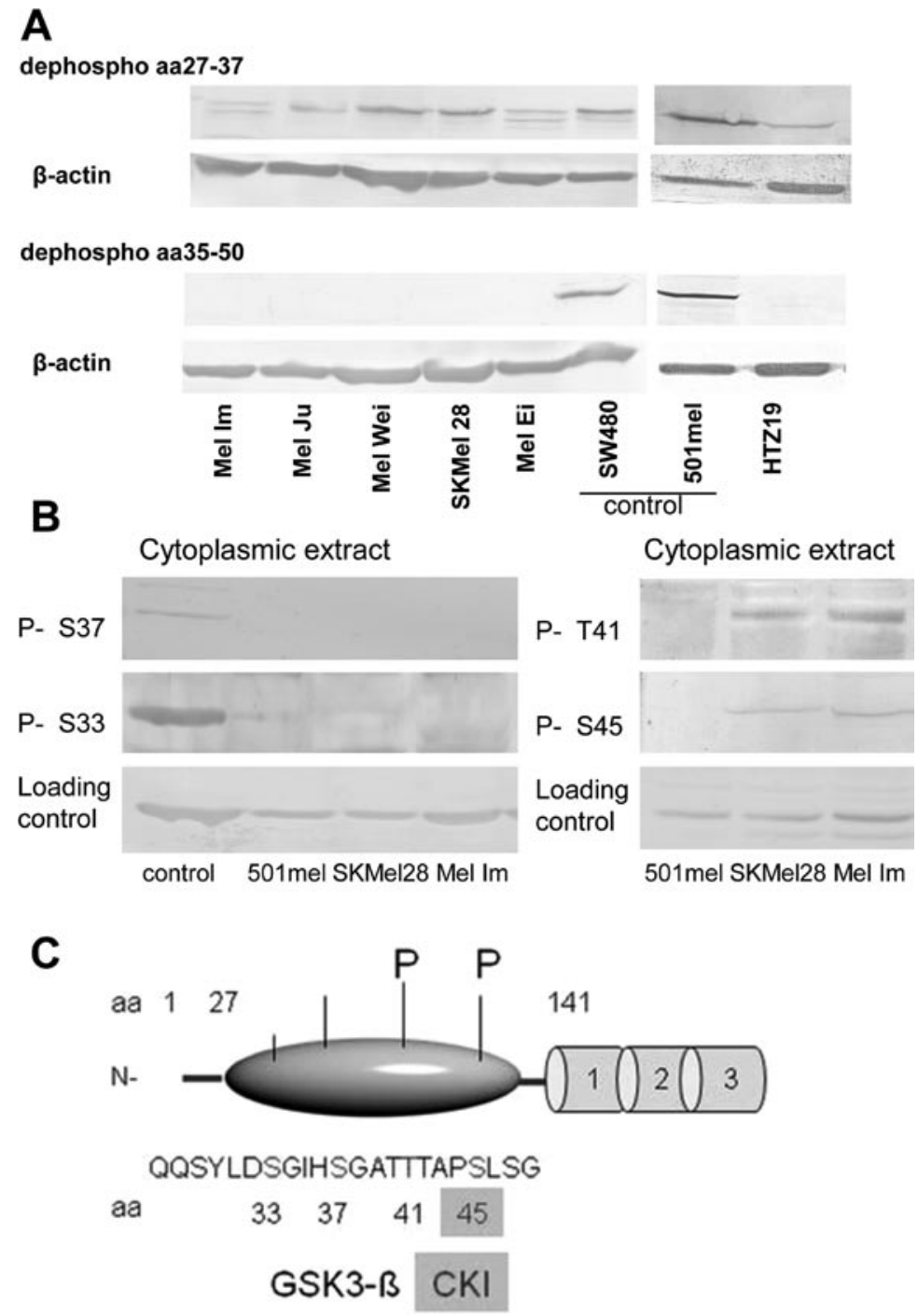

Figure 3. Analyses of the phosphorylation status of $\beta$-catenin. (A) Top, Western blot with anti-hypophosphorylated $\beta$-catenin antibody (amino acids 27-37). Bottom, Western blot with anti-hypophosphorylated $\beta$-catenin antibody (amino acids 35-50). Lysates of nine melanoma cell lines (Mel Im, Mel Ju, Mel Wei, SKMel28, Mel Ei, 501 mel, HTZ19d, Mel Juso and SKMel3) and the colon carcinoma cell line SW480 were analyzed. The positive controls for hypophosphorylated $\beta$-catenin were the cell lines $501 \mathrm{mel}$ and SW480. Absence of signals in the melanoma cell lines suggests phosphorylation at the positions aa41 and aa45. (B) Western blots with anti-phosphorylated $\beta$-catenin antibody (amino acids serine 33, serine 37, threonine 41 and serine 45 ) were performed. Cytoplasmic extracts of three melanoma cell lines (Mel Im, SKMel28 and 501 mel) are shown. The positive control for phosphorylated $\beta$-catenin was protein lysate from the breast cancer cell line SW626 and the kidney cell line 293T. (C) Schematic overview of $\beta$-catenin N-terminal phosphorylation status of SKMel28 and Mel Im. P, phosphorylation; aa, amino acids.

phosphorylated at these sites. To assess the possibility that the defined phosphorylation pattern in melanoma is regulating the activity we used wild-type $\beta$-catenin, T41A and S45A $\beta$-catenin mutant constructs. A comparison of TOPflash activity after transfection of all constructs revealed lack of activity of wildtype and S45A $\beta$-catenin, interestingly, T41A resulted in an induction (Fig. 4A). The efficiency of transient transfection of these constructs was examined using quantitative real-time PCR (data not shown).

Having found transcriptional activity of the T41A mutant, we consequently examined mRNA expression of known target genes of $\beta$-catenin/LEF/TCF after transfection of wild-type $\beta$-catenin, T41A and S45A into Mel Im cells. As example, we observed induction in Brn-2 expression after expression of T41A in the Mel Im cell line (Fig. 4B). We performed further quantitative real-time PCR for the target genes MMP1,
MMP3, MMP9, BMP2 Osteopontin, MITF and Conductin (data not shown) and confirmed the result shown in Fig. 4B. This further supports that partial phosphorylation of endogeneous $\beta$-catenin is the reason for transcriptional inactivity of endogenous $\beta$-catenin in malignant melanoma cells. Western blot results showed the phosphorylation of threonine 41 and serine 45 of endogenous $\beta$-catenin in several analyzed melanoma cell lines.

\section{Discussion}

Melanoma cells prefer the $\beta$-catenin-independent non-canonical signaling pathway. The involvement of canonical Wnt signaling in melanocyte embryogenesis and development is of great importance. Wnt signals (mainly Wnt1 and Wnt3a) have been implicated in the induction, migration and differentiation 
A
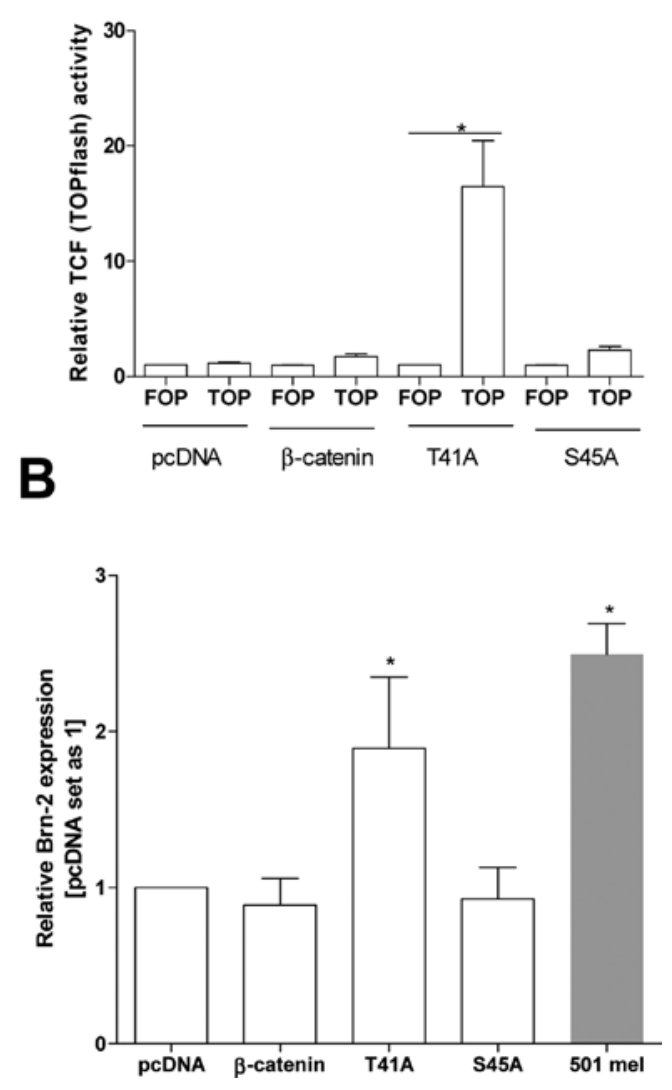

Figure 4. Influence of the mutant forms of $\beta$-catenin in malignant melanoma. (A) Luciferase experiments with TOPflash and FOPflash reporter construct were performed with the melanoma cell line Mel Im to analyze the influence of wild-type $\beta$-catenin, T41A and S45A mutant construct of $\beta$-catenin on LEF/TCF regulation. FOPflash results were set as 1 and the transfection efficiency was proofed with a renilla pRLTK construct. (" $\mathrm{p}<0.05$; ns, not significant). (B) Quantitative real-time PCR of $\beta$-catenin target gene Brn-2 after transfection of wild-type $\beta$-catenin, T41A and S45A variants of $\beta$-catenin. The expression status is in comparison to the positive control 501 mel.

of melanocytes from the neural crest. Interestingly, these two Wnts were not detected during migration or invasion events of melanoma cells. More importantly, Chien et al (18) claimed that Wnt3a promotes the induction of markers for melanocytic differentiation in melanoma cells leading to decreased proliferation and upregulation of melanocytic genes (18). In accordance with these findings, changes of molecules regulated by the canonical $\beta$-catenin signaling are discussed controversially for malignant melanoma and mutations of molecules of the $W n t / \beta$-catenin signaling pathway are rare. Mutations of APC (Adenomatous polyposi coli) were found in only 3-7\% of melanomas $(15,16,29)$ and of $\beta$-catenin $(C T N N B 1)$ in only $2-22 \%(14,15,28)$. In comparison, APC mutations in colorectal cancer were found with an $80 \%$ frequency.

To clarify the role of $\beta$-catenin signaling in malignant melanoma we performed detailed analyses. We could clearly demonstrate that $\beta$-catenin is mainly distributed in the cytoplasm of melanoma cells in vivo and under culture conditions. Studies of Maelandsmo et al and Pecina-Slaus et al support this finding $(21,30)$. In only 5.6 or $6.4 \%$, respectively, of the analyzed samples nuclear localization of $\beta$-catenin was observed by immunohistochemistry. Kielhorn et al have also shown that $86 \%$ of totally 157 melanoma cases retained normal membranous $\beta$-catenin staining. Additionally, a publication of Kageshita et al showed that loss of $\beta$-catenin expression is associated with disease progression in malignant melanoma (20) supporting our finding that transcriptional activity of $\beta$-catenin is reduced in melanoma.

With further experiments we tried to elucidate $\beta$-catenin modification and $\beta$-catenin regulation in melanoma cell lines. $\beta$-catenin degradation is initiated upon amino-terminal serine/threonine phosphorylation. GSK-3 $\beta$ phosphorylates the amino acids serine 33, 37 and threonine at position $41(31,32)$. The phosphorylation of the $\mathrm{N}$-terminal serine at position 45 is accomplished by CKI. $\beta$-catenin phosphorylation at these four phospho-S/T residues is critical for $\beta$-catenin recognition by the F-box protein $\beta$-Trcp, which is the specificity component of a ubiquitination apparatus $(33,34)$. The significance of $\mathbf{S 3 3}$, S37, T41 and S45 phosphorylation in degradation is underlined by the observation that mutations at these $\mathrm{S} / \mathrm{T}$ residues frequently occur in human colorectal cancer and several other malignancies $(29,35,36)$.

We analyzed the phosphorylation of these amino acids in several malignant melanoma cells in comparison to the melanoma cell line 501 mel (described as having an active Wnt/ $\beta$-catenin pathway) and determined remarkable phosphorylation at the positions T41 and S45. The occurrence of two phosphorylated and two hypophosphorylated amino acids at the $\mathrm{N}$-terminal region can lead to a non-degradable but also non-nuclear active $\beta$-catenin. That partial phosphorylation of $\beta$-catenin does not lead automatically to degradation of the protein was also shown by Kielhorn et al (37). The group found phospho- $\beta$-catenin in the nucleus of melanomas in vivo.

Surprisingly, the transfection of the T41A hypophosphorylated variant activates the transcriptional activity of the TOPflash promoter system and expression of classical $\beta$-catenin target genes. We assume that T41 phosphorylation in several melanoma cell lines, like SKMel28 and Mel Im, prevents transcriptional activity of $\beta$-catenin. To summarize, incomplete phosphorylation as found in melanoma protects $\beta$-catenin from degradation but the transcriptional activity is not completely attained.

In general, the discrepancy in $\beta$-catenin function when comparing melanoma cells to epithelial cell types can be due to the embryological origin of the cells. Nuclear function of $\beta$-catenin and activation of the canonical $\beta$-catenin pathway was predominantly described for epithelial cell types (38). As melanocytes are derived from the neural crest, cellular determinations can be clearly different. Classical cellular processes such as EMT (epithelial mesenchymal transition) are commonly described using epithelial cells. Certain changes such as upregulation of snail and down-regulation of E-cadherin can be similar in melanoma cells, however, other changes as shown for $\beta$-catenin can differ (38-40).

The question remains whether the cytoplasmic $\beta$-catenin is 'useless' for malignant melanoma cells or whether it entails an alternative signaling pathway. Our group has recently shown that the cytoplasmic $\beta$-catenin has alternative signaling functions beside transcriptional activation of LEF/TCF. We analyzed this alternative pathway because the overall results shown confirmed no classical nuclear function of $\beta$-catenin in malignant melanoma. We have previously shown that 
$\beta$-catenin can activate the MAPkinase $\mathrm{p} 38$ and NF- $\mathrm{kB}$ in the cytoplasm of melanoma cell lines (22). This effect was inducible through the transfection of a $\beta$-catenin expression construct which increased the whole $\beta$-catenin protein amount in the cytoplasm of the cells (22).

However, further investigations are necessary to clarify the mechanisms of modification of $\beta$-catenin in malignant melanoma which on the one hand regulates the cytoplasmic signaling cascade of $\beta$-catenin and on the other hand averts the canonical signaling in malignant melanoma. In summary, we have demonstrated a new signaling function of $\beta$-catenin which could be regulated by phosphorylation.

\section{Acknowledgements}

We are indebted to David L. Rimm's lab (Department of Pathology, Yale University School of Medicine, New Haven) for the $\beta$-catenin mutant constructs, J. Behrens (Department of Experimental Medicine II, University of Erlangen, Germany) for the pBAT- $\beta$-catenin construct and Claudia Wellbrock (University of Manchester, UK) for the 501 mel cell line.

\section{References}

1. Kemler R: From cadherins to catenins: cytoplasmic protein interactions and regulation of cell adhesion. Trends Genet 9: 317-321, 1993.

2. Kolligs FT, Bommer G and Goke B: Wnt/beta-catenin/tcf signaling: a critical pathway in gastrointestinal tumorigenesis. Digestion 66: 131-144, 2002.

3. Logan CY and Nusse R: The Wnt signaling pathway in development and disease. Annu Rev Cell Dev Biol 20: 781-810, 2004.

4. Wharton KA Jr: Runnin' with the Dvl: proteins that associate with Dsh/Dvl and their significance to Wnt signal transduction. Dev Biol 253: 1-17, 2003.

5. Mao J, Wang J, Liu B, Pan W, Farr GH, III, Flynn C, Yuan H, Takada S, Kimelman D, Li L and Wu D: Low-density lipoprotein receptor-related protein-5 binds to Axin and regulates the canonical Wnt signaling pathway. Mol Cell 7: 801-809, 2001.

6. Staal FJ, Noort MM, Strous GJ and Clevers HC: Wnt signals are transmitted through N-terminally dephosphorylated betacatenin. EMBO Rep 3: 63-68, 2002.

7. Slusarski DC, Yang-Snyder J, Busa WB and Moon RT: Modulation of embryonic intracellular $\mathrm{Ca}^{2+}$ signaling by Wnt-5A. Dev Biol 182: 114-120, 1997.

8. Weeraratna AT: A Wnt-er wonderland - the complexity of Wnt signaling in melanoma. Cancer Metastasis Rev 24: 237-250, 2005.

9. Weeraratna AT, Jiang Y, Hostetter G, Rosenblatt K, Duray P, Bittner M and Trent JM: Wnt5a signaling directly affects cell motility and invasion of metastatic melanoma. Cancer Cell 1: 279-288, 2002

10. Rivera MN, Kim WJ, Wells J, Driscoll DR, Brannigan BW, Han M, Kim JC, Feinberg AP, Gerald WL, Vargas SO, Chin L, Iafrate AJ, Bell DW and Haber DA: An X chromosome gene, WTX, is commonly inactivated in Wilms tumor. Science 315: 642-645, 2007.

11. Koesters R, Ridder R, Kopp-Schneider A, Betts D, Adams V, Niggli F, Briner J and von Knebel DM: Mutational activation of the beta-catenin proto-oncogene is a common event in the development of Wilms' tumors. Cancer Res 59: 3880-3882, 1999.

12. Laken SJ, Papadopoulos N, Petersen GM, Gruber SB, Hamilton SR, Giardiello FM, Brensinger JD, Vogelstein B and Kinzler KW: Analysis of masked mutations in familial adenomatous polyposis. Proc Natl Acad Sci USA 96: 2322-2326, 1999.

13. Fukushima H, Yamamoto H, Itoh F, Horiuchi S, Min Y, Iku S and Imai K: Frequent alterations of the beta-catenin and TCF-4 genes, but not of the APC gene, in colon cancers with highfrequency microsatellite instability. J Exp Clin Cancer Res 20: $553-559,2001$.
14. Rimm DL, Caca K, Hu G, Harrison FB and Fearon ER: Frequent nuclear/cytoplasmic localization of beta-catenin without exon 3 mutations in malignant melanoma. Am J Pathol 154: 325-329, 1999.

15. Reifenberger J, Knobbe CB, Wolter M, Blaschke B, Schulte KW, Pietsch T, Ruzicka T and Reifenberger G: Molecular genetic analysis of malignant melanomas for aberrations of the WNT signaling pathway genes CTNNB1, APC, ICAT and BTRC. Int J Cancer 100: 549-556, 2002.

16. Worm J, Christensen C, Gronbaek K, Tulchinsky E and Guldberg P: Genetic and epigenetic alterations of the APC gene in malignant melanoma. Oncogene 23: 5215-5226, 2004.

17. Larue L and Delmas V: The WNT/Beta-catenin pathway in melanoma. Front Biosci 11: 733-742, 2006.

18. Chien AJ, Moore EC, Lonsdorf AS, Kulikauskas RM, Rothberg BG, Berger AJ, Major MB, Hwang ST, Rimm DL and Moon RT: Activated Wnt/beta-catenin signaling in melanoma is associated with decreased proliferation in patient tumors and a murine melanoma model. Proc Natl Acad Sci USA 106: 1193-1198, 2009.

19. Bachmann IM, Straume O, Puntervoll HE, Kalvenes MB and Akslen LA: Importance of P-cadherin, beta-catenin, and Wnt5a/ frizzled for progression of melanocytic tumors and prognosis in cutaneous melanoma. Clin Cancer Res 11: 8606-8614, 2005.

20. Kageshita T, Hamby CV, Ishihara T, Matsumoto K, Saida T and Ono T: Loss of beta-catenin expression associated with disease progression in malignant melanoma. Br J Dermatol 145: 210-216, 2001.

21. Maelandsmo GM, Holm R, Nesland JM, Fodstad O and Florenes VA: Reduced beta-catenin expression in the cytoplasm of advanced-stage superficial spreading malignant melanoma. Clin Cancer Res 9: 3383-3388, 2003.

22. Kuphal S, Poser I, Jobin C, Hellerbrand C and Bosserhoff AK: Loss of E-cadherin leads to upregulation of NFkappaB activity in malignant melanoma. Oncogene 23: 8509-8519, 2004.

23. Kuphal $S$ and Bosserhoff AK: Influence of the cytoplasmic domain of E-cadherin on endogenous $\mathrm{N}$-cadherin expression in malignant melanoma. Oncogene 25: 248-259, 2006.

24. Denk AE, Bettstetter M, Wild PJ, Hoek K, Bataille F, Dietmaier W and Bosserhoff AK: Loss of maspin expression contributes to a more invasive potential in malignant melanoma. Pigment Cell Res 20: 112-119, 2007.

25. Halaban R, Krauthammer M, Pelizzola M, Cheng E, Kovacs D, Sznol M, Ariyan S, Narayan D, Bacchiocchi A, Molinaro A, Kluger Y, Deng M, Tran N, Zhang W, Picardo M and Enghild JJ: Integrative analysis of epigenetic modulation in melanoma cell response to decitabine: clinical implications. PLoS One 4: e4563, 2009.

26. Provost E, Yamamoto Y, Lizardi I, Stern J, D'Aquila TG, Gaynor RB and Rimm DL: Functional correlates of mutations in beta-catenin exon 3 phosphorylation sites. J Biol Chem 278: 31781-31789, 2003.

27. Rothhammer T, Bataille F, Spruss T, Eissner G and Bosserhoff AK: Functional implication of BMP4 expression on angiogenesis in malignant melanoma. Oncogene 26: 4158-4170, 2007.

28. Rubinfeld B, Robbins P, El Gamil M, Albert I, Porfiri E and Polakis P: Stabilization of beta-catenin by genetic defects in melanoma cell lines. Science 275: 1790-1792, 1997.

29. Rubinfeld B, Albert I, Porfiri E, Munemitsu S and Polakis P: Loss of beta-catenin regulation by the APC tumor suppressor protein correlates with loss of structure due to common somatic mutations of the gene. Cancer Res 57: 4624-4630, 1997.

30. Pecina-Slaus N, Zigmund M, Kusec V, Martic TN, Cacic M and Slaus M: E-cadherin and beta-catenin expression patterns in malignant melanoma assessed by image analysis. J Cutan Pathol 34: 239-246, 2007.

31. Liu C, Li Y, Semenov M, Han C, Baeg GH, Tan Y, Zhang Z, Lin $\mathrm{X}$ and $\mathrm{He} \mathrm{X}$ : Control of beta-catenin phosphorylation/ degradation by a dual-kinase mechanism. Cell 108: 837-847, 2002.

32. Amit S, Hatzubai A, Birman Y, Andersen JS, Ben Shushan E, Mann M, Ben Neriah Y and Alkalay I: Axin-mediated CKI phosphorylation of beta-catenin at Ser 45: a molecular switch for the Wnt pathway. Genes Dev 16: 1066-1076, 2002.

33. Winston JT, Strack P, Beer-Romero P, Chu CY, Elledge SJ and Harper JW: The SCFbeta-TRCP-ubiquitin ligase complex associates specifically with phosphorylated destruction motifs in IkappaBalpha and beta-catenin and stimulates IkappaBalpha ubiquitination in vitro. Genes Dev 13: 270-283, 1999. 
34. Hart M, Concordet JP, Lassot I, Albert I, del los SR, Durand H, Perret C, Rubinfeld B, Margottin F, Benarous R and Polakis P: The F-box protein beta-TrCP associates with phosphorylated beta-catenin and regulates its activity in the cell. Curr Biol 9: 207-210, 1999.

35. Morin PJ, Sparks AB, Korinek V, Barker N, Clevers H, Vogelstein B and Kinzler KW: Activation of beta-catenin-Tcf signaling in colon cancer by mutations in beta-catenin or APC. Science 275 : 1787-1790, 1997.

36. Spink KE, Polakis $P$ and Weis WI: Structural basis of the Axinadenomatous polyposis coli interaction. EMBO J 19: 2270-2279, 2000

37. Kielhorn E, Provost E, Olsen D, D'Aquila TG, Smith BL, Camp RL and Rimm DL: Tissue microarray-based analysis shows phospho-beta-catenin expression in malignant melanoma is associated with poor outcome. Int J Cancer 103: 652-656, 2003.
38. Birchmeier C, Birchmeier W and Brand-Saberi B: Epithelialmesenchymal transitions in cancer progression. Acta Anat (Basel) 156: 217-226, 1996.

39. Kim K, Daniels KJ and Hay ED: Tissue-specific expression of beta-catenin in normal mesenchyme and uveal melanomas and its effect on invasiveness. Exp Cell Res 245: 79-90, 1998.

40. Behrens J, Vakaet L, Friis R, Winterhager E, Van Roy F, Mareel MM and Birchmeier W: Loss of epithelial differentiation and gain of invasiveness correlates with tyrosine phosphorylation of the E-cadherin/beta-catenin complex in cells transformed with a temperature-sensitive v-SRC gene. J Cell Biol 120: 757-766, 1993. 